

\title{
The Effects of Mobile Hotel Applications (MHA) on Customer Behavioral Intention to Reuse and Revisit
}

\author{
Maher Fouad Hossny
}

Hotel management Department, Cairo higher institute for tourism and hotels.

\section{ARTICLE INFO ABSTRACT}

Keywords:

Mobile hotel app;

PEOU; PU;

Memorable;

Experience;

Satisfaction;

Behavioral Intention.

\section{(JAAUTH) \\ Vol. 21, No. 4, (December 2021),} PP.172-193.
Recently, contactless has become one of the biggest challenges facing the hospitality industry. Everywhere, the pandemic has forced hotel companies to adapt to safer measures and to strive to reduce contact points. Mobile hotel applications have become one of the most important communication channels provided by hotels for booking, and services with less staff contact. The purpose of this study is to investigate a framework model that integrates the technology acceptance model (TAM) model with the antecedents of a customer's behavioral intention to reuse the hotel's mobile app in the context of hotel reservations and use of services. The suggested model has been tested utilising structure equation analysis model "SEM". A descriptive data collected from 204 customers who used the hotel's mobile app. Study results revealed that perceived usefulness (PU) had a significant impact on the customer memorable experience (ME) toward mobile hotel apps (MHA) technology. Furthermore, the memorable experience boosts customer satisfaction and, as a result, enhances consumer behavioural intention, resulting in increased app reuse and revisit. The findings of the study lead to the growth of hotel mobile applications as an engaging tool for hotel guest retention as well as a successful marketing tool for attracting new visitors in a highly competitive marketplace. The study's findings provide useful practical information for a variety of stakeholders, including hotel managers and IT managers in hospitality and travel industry.

\section{1- Introduction}

During the early years of the COVID pandemic, many people have become concerned about safety, cleanliness, and have gradually become comfortable with human interaction outside of their immediate family circles. As people resume their travels, they become more conscious of how hotels are implementing new technologies to make customers and travelers feel safe and secure. Among the several new technologies, MHA has become one of the most important communication channels provided by hotels that support and enable contactless service and it could be at the frontline of travelers' minds. Mobile apps are software application systems designed for mobile device operating system platforms that extend the phone's capabilities by 
allowing users to perform specific functions (Yang, 2013; Dube \& Helkkula, 2015; Kim \& Ah Yu, 2016). Mobile hotel applications are created to meet specific client requirements and can boost the efficiency of a variety of mobile operations. Furthermore, because businesses may contribute to the continual improvement of app services, this trend gives customers more opportunities to access the smart app's features, supporting the hotel industry's rapid expansion. (Dickinson et al., 2014).

Customer experience with hotel apps may be used to determine whether or not guest expectations were met, as well as to assess what is essential to customers, making customer experience with hotel apps a beneficial source of information for hotels. Hotel customers can generate expectations and impressions of service quality for the products and/or services they are considering by seeing hotel rooms, lobbies, and the outside appearance of buildings, as well as having access to a range of advanced features via hotel applications. According to Carlino (2015), hotel smart apps play a significant role in offering hotel app customers the highest process of integrating and personalizing a digital universe of personalizing and customizing hotel app consumer engagement. By using hotel mobile apps, hotel customers may generate experience values in their digital marketplace, which can affect customer satisfaction and willingness to revisit.

Customer behaviour while utilising an innovative technology or tool is determined by their impressions of that technology or application, which are influenced by two major factors: behavioural intention and perceived usefulness. According to a research conducted by Herrero and Martin (2012), the perceived usefulness of modern technological influences customers' attitudes and judgments of ease of use. Customers' attitudes toward modern technology, according to Kaplanidou and Vogt (2006) and Ayeh (2015), can have a significant impact on its acceptance and usage during a visit or stay. As a result, it may be claimed that we should consider the influence of external variables connected to new technology development on visitors' perceptions and convenience of use.

The online experience was recognized by Pandemic as an important component of the actual service encounter. It's essential to consider the online experience as an extension of the real-life service experience (Chung et al., 2018; Tussyadiah and Park, 2018). Memorable experiences are widely regarded as a reliable predictor of actual behavior. A memorable experience (ME) is defined as the ability of clients to remember and recall past experience (Kim and Chen, 2019; Kim and Ritchie, 2014; Tung and Ritchie, 2011). One of the most positive consequences of customer experience is memorability, which influences level of customer satisfaction (Jiang et al., 2016; Vada et al., 2019). Revisit hotel brands are becoming popular in hospitality studies. As a result, additional research is recommended to better understand how MHA technologies will improve memorable experience and customer satisfaction as the best predictors of subsequent behavior. (Lee et al., 2018; Jeong and Shin, 2019). Thus, this study aims to develop a theoretical framework to investigate the relationships between the technology acceptance model (TAM) model, memorable experience, customer satisfaction, as well as behavioral intent to reuse hotel 
applications and revisit. In particular, the following research questions were discussed in this study:

Q1. What impact will technology acceptance model have on memorable experiences?

Q2: Does a memorable experience increase a visitor's satisfaction and behavioral intention to reuse the app and revisit the hotel?

\section{2- Theoretical background}

\subsection{Technology Acceptance Model (TAM)}

The theoretical basis and research design of this study are based on "the Technology Acceptance Model (TAM)" by (Davis, 1989). Davis (1986) proposed that two variables might explain a user's desire to explore new technology: "perceived ease of use and perceived usefulness". The first antecedent is PU, which is described as the degree to which potential users believe that the use of technology will improve their performance (Davis, 1989). Rather, PEOU refers to the extent to which potential users believe that the use of new technologies will be effortless (Davis, 1989). However, the final version of TAM only contains "PU and PEOU" because it is more concise. For example, Meuter et al. (2000) indicated that simplicity of use and convenience influence consumer satisfaction with self-service technology. Since then, TAM has been used in numerous researches to investigate the use of mobile technologies in the accommodation sector. (Kim and Qu, 2014; Kim, 2016; Kwon et al., 2013; Wang and Wang, 2010).

TAM is essential in the hospitality context because it describes how people learn to embrace and employ technology. TAM proposed that when customers are exposed to a different technology (such as a mobile hotel app), the PEOU of that technology should affect their decision whether or not to use it. The impact of PEOU on technology adoption has been extensively researched. However, initial role of technology does not guarantee that it will be used in the future (Hong et al., 2006; Hsieh et al., 2008). As a result, even if users initially intend to use the technology, they can stop using it at any time if they think it is difficult to use and needs more time. Therefore, the following hypothesis was tested.

Hypothesis 1: Perceived ease of use has a positive and direct effect on perceived usefulness.

\subsection{Memorable experience (ME)}

Despite past research into the identification of applications, concepts, and impact of mobile hotel apps, the value of experience derived from guest experience on hotel apps has been given little attention. It is essential to focus on the customer experience that hotel guests perceive with hotel apps, as this experience can have a significant role to play in hotel choice (Wang, Xiang, 2016). To enhance the customer experience, hotel mobile apps can associate to other services and facilities. Hotels provided guests with a single hub they can use at any time (Lin, 2015).

Some recent studies have investigated the link between provided satisfaction and, service experience and have reported significant results (Bravo et al., 2019; Ali et al., 2016). This research model based on the experience of the service provided has been 
increasing in magnitude and complexity, solving dependent structures other than simple satisfaction. Various service experience models have been tested and verified, leading to satisfaction, price acceptance, willingness to visit again, etc. (Ali et al., 2016). Furthermore, the previous research by Dickinson et al. (2014) has shown that mobile hotel apps play an important role in improving customers' experience nowadays. As a result, the popularity and utilization of mobile hotel apps have increased massively in recent years and will likely remain a major interest in the hospitality industry in the future.

The inherent characteristics of tourists can affect the way a tourist perceives and uses technology, while different experiences are motivated by location and trip aspects (Femenia-Serra, 2018). Also, a memorable travel experience is considered an important predictor of future behavior. The ability of visitors to recognize and recollect activities that have occurred is referred to as memorable experiences (Kim and Chen, 2019; Kim and Ritchie, 2014; Tung and Ritchie, 2011). In this section, one of the most important outcomes of a tourist experience is memorability, which influences tourist satisfaction (Vada et al., 2019). The new concepts related to the satisfaction and behavioral intentions of customers have received increasing attention in tourism and hospitality research. As a result, more research is urged in order to gain a deeper understanding of how smart tourism technology will create a memorable travel experience (Lee et al., 2018). Several studies investigated the effect of theme park guests' experiences on tourists' behavioral intentions. The findings suggest that experience influences behavioral intention indirectly through satisfaction and memory (Jeong and Shin, 2019; Lee et al., 2018; Manthiou et al. 2016).

Benur and Bramwell (2015) stated that "travel products are fundamental experiences", and the experience is considered the core of tourist choice and satisfaction. Travel experiences are not only influenced by tangible products and experiential services, but to a certain extent, specific experiences are unforgettable and therefore memorable (Cornelisse, 2014). According to Chandralal et al. (2015), the importance of the Memorable Experiences theory derives from the notion that memories of previous consumer experiences often have a substantial influence on consumer decisionmaking circumstances. Kim et al. (2012) explained the aspects of the experience identified by various researchers to aid in understanding the travel experience. "Participation, hedonism, happiness, pleasure, relaxation, stimulation, refreshing, social interaction, spontaneity, meaning, knowledge, challenge, sense of separation, eternity, adventure, personal relevance, novelty, avoidance of stress, and intellectual development" are some of these components. Memorable Experiences (MEs) are experiences that may be remembered and recalled after a journey that is selectively created from tourist encounters. MEs are more essential since only remembered experiences affect future visitor decisions (Kim et al. 2010). Tourists make decisions based on prior experiences and recollections to plan future visits (Lehto et al., 2004; Wirtz, et al., 2003).

A Memorable Experience (ME) requires a personal assessment of the travel experience (Kim et al., 2012). ME refers to the memorable experiences of tourists, especially the feelings and emotions they experience during tourist activities (Lee, 
2015). However, none of the previous studies considered the influence of TAM factors on user satisfaction in mobile hotel applications (MHA). Therefore, the following hypotheses were proposed in this study:

Hypothesis 2: Perceived ease of use of MHA has a positive and direct effect on memorable experiences.

Hypothesis 3: Perceived usefulness of MHA has a positive and direct effect on a memorable experience.

\subsection{Customer Satisfaction}

Many studies have identified the link between customer satisfaction and experience. This relationship is highlighted as a predictor for better understanding future behavior of customers (Gallarza \& Saura, 2006; Lee et al., 2007 Jin et al., 2015). Customer satisfaction is the most critical cornerstone of the hospitality industry. Customer satisfaction results from a positive experience following the purchase of a product or the use of a service that meets expectations (Bogicevic et al., 2016). To attain consumer satisfaction, businesses must increasingly concentrate on the usefulness and dependability of their products and services. According to Chu (2002), Customer satisfaction is a major goal for most businesses because it is linked to company sales growth. A happy customer is an important part of a company's business plan for lowering the marketing budget. Unlike classical face-to-face assistance, MHA improves service delivery through speed, detail, and customization, resulting in higher client satisfaction (Pantano \& Viassone, 2015). The usage of branded applications minimizes any delay that customers could experience while waiting for support. A study by De Cannière et al., (2010) shows that disconfirmation of beliefs and confirmation of expectations have a direct impact on satisfaction. The positive effect of using branded apps is the ability to stimulate a satisfying emotional response. Consumers who have had a positive experience with the branded applications are more likely to exhibit positive continuation intention, which leads to repeat consumption.

Satisfaction is seen as the key to establishing and maintaining the foundation of longterm consumer loyalty. When people perceive their real experience to their initial expectations and discover that the expected service or quality of the experience has been confirmed, they will be satisfied (Chen et al., 2012; Fang et al., 2017). Boo and Busser (2018), on the other hand, discovered that if guest expectations are reliable with the implied performance of hotel services provided, the post-satisfaction with these services is considerable. Chen et al. (2012) showed that expectations directly affected perceptions of real experience and satisfaction. Therefore, the following hypothesis was proposed.

Hypothesis 4: A memorable experience has a positive and direct effect on satisfaction.

\subsection{Behavioral Intention}

The hotel industry has demonstrated a positive correlation between satisfaction and behavioral intention (Han and Ryu, 2009; Martín-Consuegra et al., 2007). It has been shown that higher levels of satisfaction lead to higher levels of behavioral intention, 
which leads to the possibility to price tolerance and repurchase (Huber et al., 2001). Previous research indicated that dominant opinions believe that customer satisfaction has positive effect on behavioral intention (Flavián et al., 2006; Veloutsou, 2015; Kao and Lin, 2016). If customers think that a product has delivered on its promises, they are more likely to repeat the behavior in the future (Flavián et al., 2006). Yi (1990) also examined the impact of customer satisfaction on customer loyalty, asserting that "customers' satisfaction influences both purchase intentions and post-purchase behavior. Therefore, consumer participation in brand applications may increase customer intention to revisit the hotel. This can be ascertained by exploring the relationship between brand application interaction and consumer perception. Similarly, Chandralal and Valenzuela (2013) studied the causes and behavioral consequences of memorable tourism experiences (MEs) from the standpoint of Australian visitors. The study's findings indicated that memorable experiences affect future intention, namely the desire to refer to others. Satisfaction has been found to be a strong predictor of subsequent positive behavior. Customers who are dissatisfied complain, switch service providers, and spread negative word of mouth; pleased customers, on the other hand, are more likely to stay loyal, engage in useful conversations, and return whenever the conditions permit. While customer satisfaction may not be the most important technique for increasing customer return, it tends to be the greatest place to start (Tung et al., 2016).

Satisfaction and continuation intention have a direct impact on behavioral intention. Customers who are impressed with a branded app will enhance brand recognition of that app, and this behavior enables businesses to build customer retention (Gamboa et al., 2014). As a result, one could argue that customer interaction with mobile hotel apps is likely to increase behavioral intention toward a brand hotel. The findings of this study have shown significantly how successful hotel companies could use mobile applications as a lead to enhance satisfaction and upsurge the intention to reuse MHA and revisit again. This study provided (should be in the past tense; your study is already done) useful insights into what drove behavioral intention research, especially in the hotel business that lacked literature mentioning the relationship between experience, memory and customer behavioral intention. Therefore, based on the previous empirical findings, the following hypotheses were proposed:

Hypothesis 5: memorable experience has positive and direct effect on behavioral intention to re-use the app and revisit the hotel.

Hypothesis 6: satisfaction has positive and direct effect on behavioral intention to reuse the app and revisit the hotel.

Based on previous research, the author suggests a conceptual framework model in which PU, PEOU, ME, and satisfaction influence BI's behavior toward mobile hotel apps (see Figure 1). 


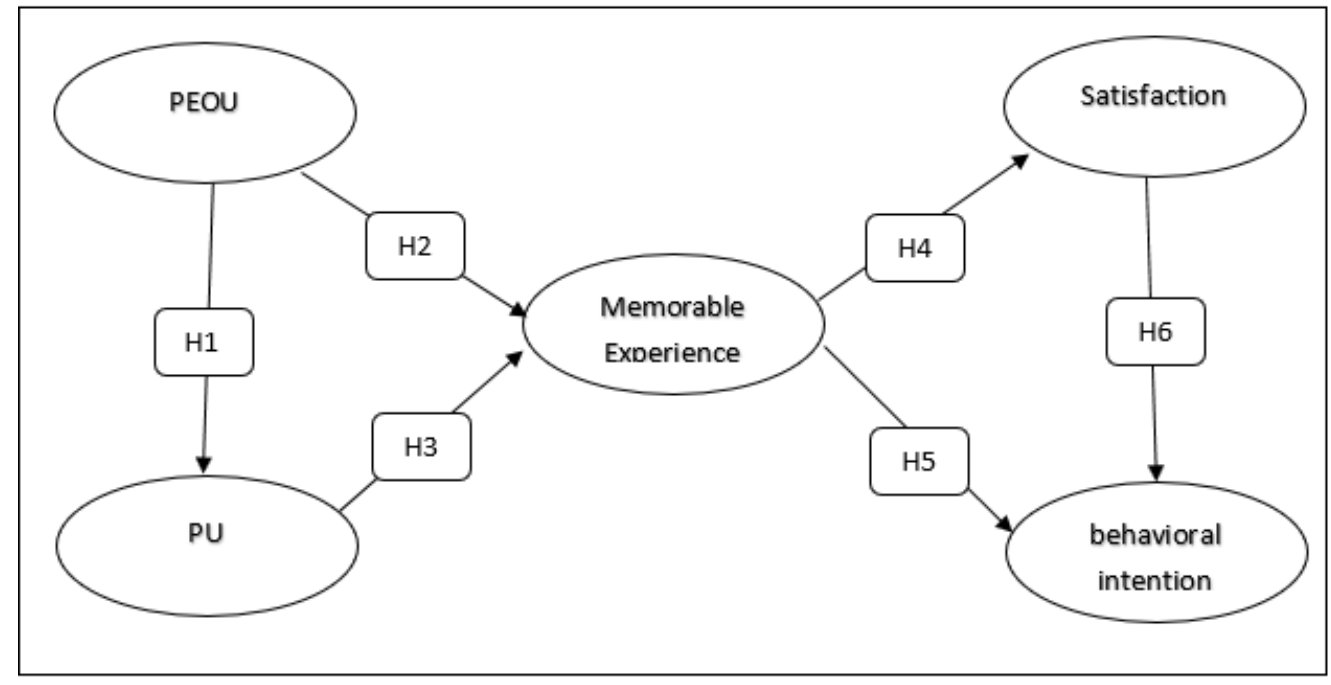

Fig.1. Conceptual model.

\section{3- Methodology}

This research proposes an incorporated model based on the TAM model, memorable experience, and satisfaction into the conceptual framework adapted from Kim (2018) describing customer behavioral intention formation. Specifically, this conceptual model predicts that the intention of hotel customers to re-use hotel apps is a result of satisfaction based on the perceived experience from perceived ease of use and perceived usefulness. The model's purpose is to see what hotel customers faced when using their hotel apps, as well as if memorable experiences gained through hotel apps influenced customer satisfaction and customer behavioral intention. The two fundamental principles TAM attributes are perceived usefulness (PU) and perceived ease of use (PEOU). This is adapted from Davis (1986) to clarify how major factors influence customers' acceptance of mobile hotel apps (Serenko and Bontis, 2004).

Davis (1986) claimed that clients' inspiration to attempt another innovation can be clarified by two factors: perceived ease of use and perceived usefulness. Davis (1989) characterized perceived usefulness as the level of an individual's should believe that the use of a mobile app would be beneficial to their lives; otherwise, they would not use them. Perceived ease of use is defined as the level of a person's belief that new technology would be easy to use and can lessen the client's endeavors. The memorable experience (ME) consisting of three variables was adapted by utilizing the one-dimensional concept suggested by Kim et al. (2018) and Jeong and Shin (2019). Four variables on a memorable experience, three variables on customer satisfaction, and three variables on customer behavioral intention were developed from Kim (2018) and Jeong and Shin (2019). This model reveals how these various components influence customer satisfaction and behavioral intention.

\subsection{Questionnaire development}

A survey design (online questionnaire) was selected to investigate the influence of the hotel's mobile app on customer behavioral intention at the selected hotel. A five-point Likert scale from "strongly disagree" (1) to "strongly agree" (5) was used to measure the perceived usefulness (PU), perceived ease of use (PEOU), memorable customer 
experiences, and customer behavioral intention dimensions. In addition, the concept of satisfaction was measured on a five-point scale from "strongly dissatisfied" (1) to "strongly satisfied" (5). The survey included four sections:

- In section one, the customers were asked to indicate if their selected hotel already had a mobile app or not.

- Section two consists of the demographic questions that would help better understand the respondents' profiles.

- In section three, the customers were asked to indicate the level of usefulness and the ease of use from the hotel mobile app.

- Section four includes questions about memorable customer experience, satisfaction, and customer behavioral intention constructs.

In total, 204 out of 280 customers completed the survey, which corresponds to a response rate of $73 \%$.

\subsection{Method of collecting data.}

The study's target population consists of domestic and international visitors who stay in hotel chains in Cairo and Alexandria from August 2020 to April 2021. Only customers who checked-in, and used the hotel's services by using the hotel's mobile app will be considered for this study. Twenty pretest questionnaires were distributed among domestic and international tourists who stayed at five-star hotel chains. The questionnaire was modified slightly, and the results of the pilot test were not utilized in any subsequent study. In five-star hotel chains, a genuine survey was performed utilizing the sampling technique to provide questionnaires to the suitable respondents., namely, Hilton, Four Seasons, Fairmont, Marriott, and Kempinski.

\subsection{Data Analysis}

To determine the cause and influence of the specified model, as well as the conceptual model's goodness of fit, the data was analysed using structural equation modelling (SEM). The data was analysed using AMOS 23. A two-step technique was employed based on Anderson et al. (1988). A confirmatory factor analysis (CFA) was used to test the validity and reliability of the construct measures. Hypothetical theoretical relationships and the suitability of the conceptual framework were then tested using the SEM.

\section{4- Results}

\subsection{Characteristics of the participants}

Study respondents were those customers who use mobile hotel apps for booking, check-in, services during stay, and check out process in five-star hotel chains in Egypt. Of the total 204 respondents, females represented $84(41 \%)$ and males 120 $(59.1 \%)$. A large number of the respondents fell into the 25 to 35 years old category represented $66 \%(n=135) ; 22 \%(n=45)$ were 36 to 45 years old; and $12 \%(n=24)$ were 46 to 66 years old. In terms of nationality composition, most of the respondents were Egyptian $-81 \%(n=165)$, and the rest represented $19 \%(n=39)$ were foreigners. 
The highest percentage was undergraduate degree holders $(70 \%, \mathrm{n}=142)$, followed by Master's degree $(20 \%, \mathrm{n}=41)$ and Ph.D. holders $(10 \%, \mathrm{n}=21)$. Educational attainment indicated that they were cultured and knowledgeable. The majority of the respondents were professionals 135 (66\%), followed by executives 69 (34\%). In addition to capturing the general profile of respondents, the collected data provided information about mobile hotel app usage, frequency of use, and the number of uses reported. Approximately $80 \%(\mathrm{n}=163)$ of the respondents had been using the app for one time a month; $20 \%(\mathrm{n}=41)$ for over 3 times a month.

\subsection{Measurement}

A set of absolute and relative fit indices were used to evaluate the overall measurement model fit. The chi-square statistics were significant since the ratio of chi-square value to degree of freedom was less than $3(1.49=253.411, \mathrm{df}=170)$. The computed Root Mean Square Error of Approximation (RMSEA) was 0.049, which was much lower than the suggested limit of 0.08. (Browne \& Cudeck, 1993). Figure 2 also demonstrated that various goodness-of-fit indicators, such as the Comparative Fit Index $(\mathrm{CFI}=0.97)$, Tucker-Lewis Index $(\mathrm{TLI}=0.96)$, Normed Fit Index $(\mathrm{NFI}=$ 0.92), Relative Fit Index (RFI $=0.90)$, and Incremental Fit Index (IFI $=0.97)$, suggested that the model fit was satisfactory (Hair, Anderson, \& Tatham, 1998).



Fig.2. Confirmatory factor analysis (CFA) 
To assess the reliability of the measurement scales, composite reliability (CR) estimates were used. Table 1 shows that the CR values were above 0.70 , indicating that construct reliability was supported (Fornell \& Larcker, 1981). Average Variance Extracted was used to assess convergent validity (AVE) and maximum shared variance (MSV) values were used.

\section{Table 1}

Validity and Reliability of Measurement Model

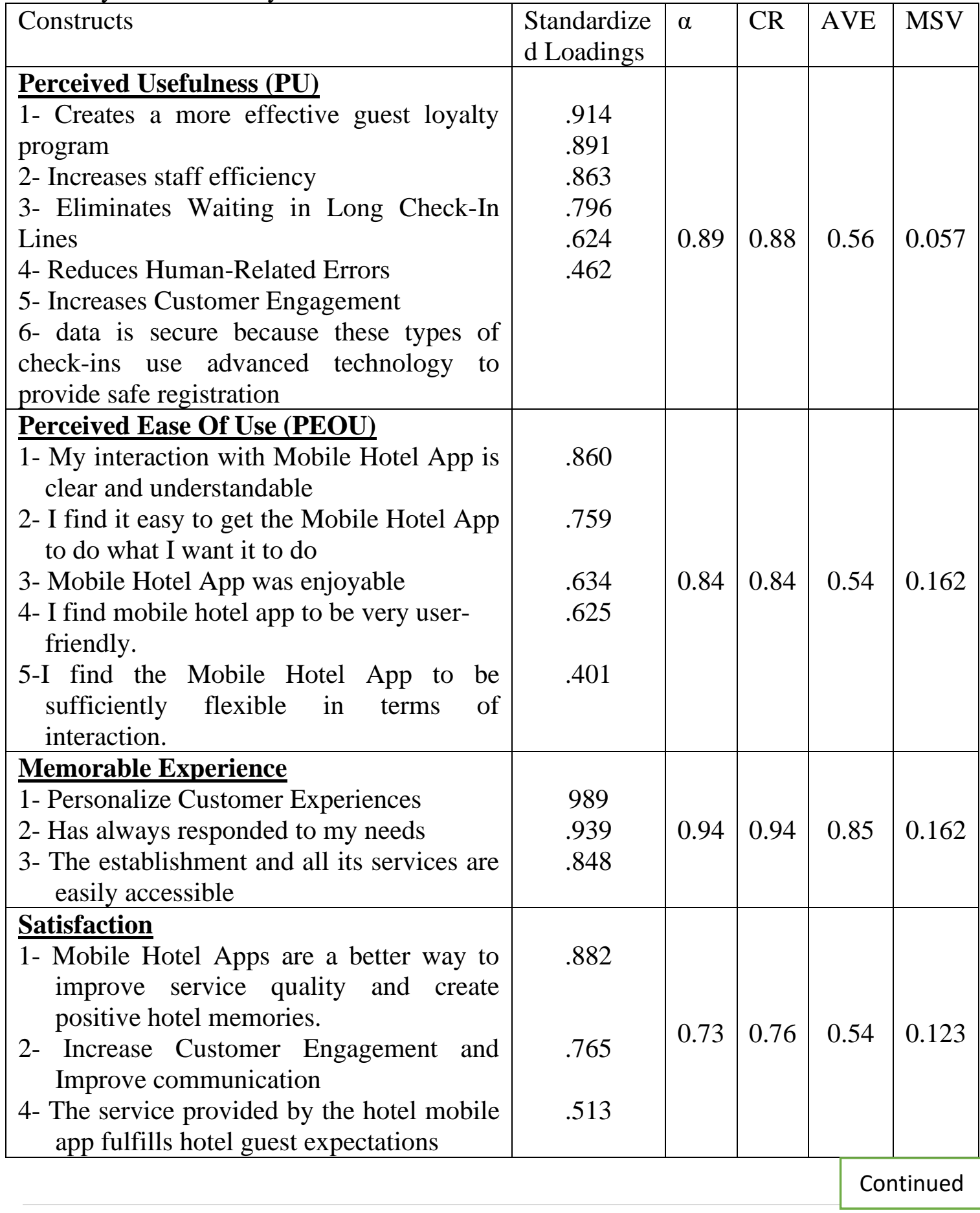




\section{Behavioral Intention}

1- By offering apps that allow location service, check in/out service, reservations, at the speed and convenience of a smartphone, allows the hotel to build a strong brand connection

2- In the future, I plan to utilize the hotel's mobile application when I stay there.

3-Mobile Hotel Apps significantly raise customer attention and commitment to hotels by focusing on direct booking with the best room rate guarantee and allowing customers to reward their earned reward points.

4-Increase brand commitment and maintain brand awareness for your hotel

.800

.766

.497

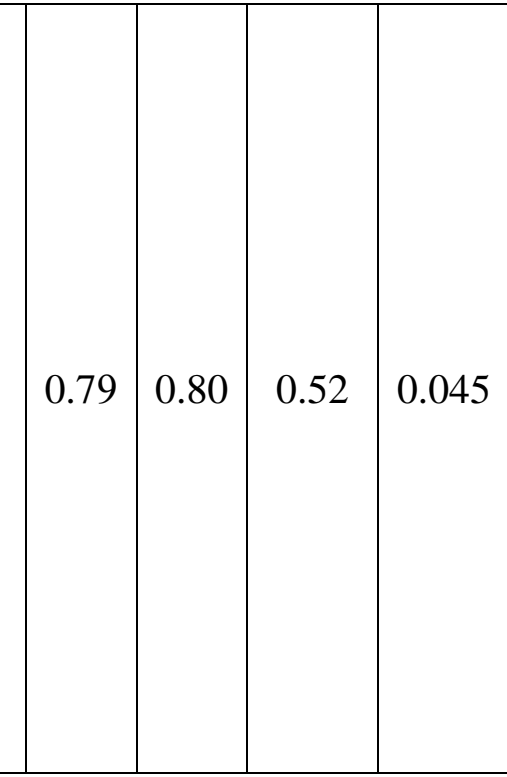

1)Cronbach's alpha, 2) Composite Reliability, 3) Average Variance Extracted, 4) Maximum Shared Variance.

Additionally, to ensure the discriminant validity, the researcher utilized the square root of AVE to test the inter-correlation amongst the tested variables (Chin, 2010). (See Table 2)

Table 2

Discriminant validity.

\begin{tabular}{|c|c|c|c|c|c|}
\hline & PU & PEOU & ME & Satisfaction & BI \\
\hline PU & 0.746 & & & & \\
\hline PEOU & $0.238^{* *}$ & 0.732 & & & \\
\hline ME & 0.114 & $0.403 * * *$ & 0.922 & & \\
\hline Satisfaction & 0.041 & $-0.351^{*} *$ & $0.229 * *$ & 0.732 & \\
\hline BI & 0.081 & $0.213^{*}$ & $0.202^{*}$ & 0.135 & 0.718 \\
\hline
\end{tabular}

The AVE value varies from 0.52 to 0.85 , which was higher than the recommended value of 0.5, indicating that the construct was valid (Fornell \& Larcker, 1981). Furthermore, discriminant validity was measured by comparing the square roots of AVE scores to construct correlations. Because the squared correlations between pairs of constructs were less than the AVE values, the results supported discriminant validity (Table 2).

\subsection{Structural Equation Modeling}

The proposed conceptual model was tested using structural equation modeling. The goodness of fit statistics demonstrated that the model fitted the data satisfactorily chisquare, $(2=1.631=287.004, \mathrm{df}=176$ (p.001), RMSEA $=.056, \mathrm{CFI}=.957, \mathrm{IFI}=.960$, $\mathrm{NFI}=.905$, AGFI=.85GFI=.883). Table 3 and Fig. 2 reveal that the proposed 
theoretical model has a high predictive potential for hotel mobile app reuse intentions. According to our model, using hotel mobile apps accounted for $16 \%$ of the overall variation in memorable experiences. The suggested model also accurately predicted guest satisfaction, accounting for $36 \%$ of the total. Four study factors, PEOU, PU, $\mathrm{ME}$, and Satisfaction, explained around $36 \%$ of the variance in behavioral intention to re-use hotel mobile applications and revisit.

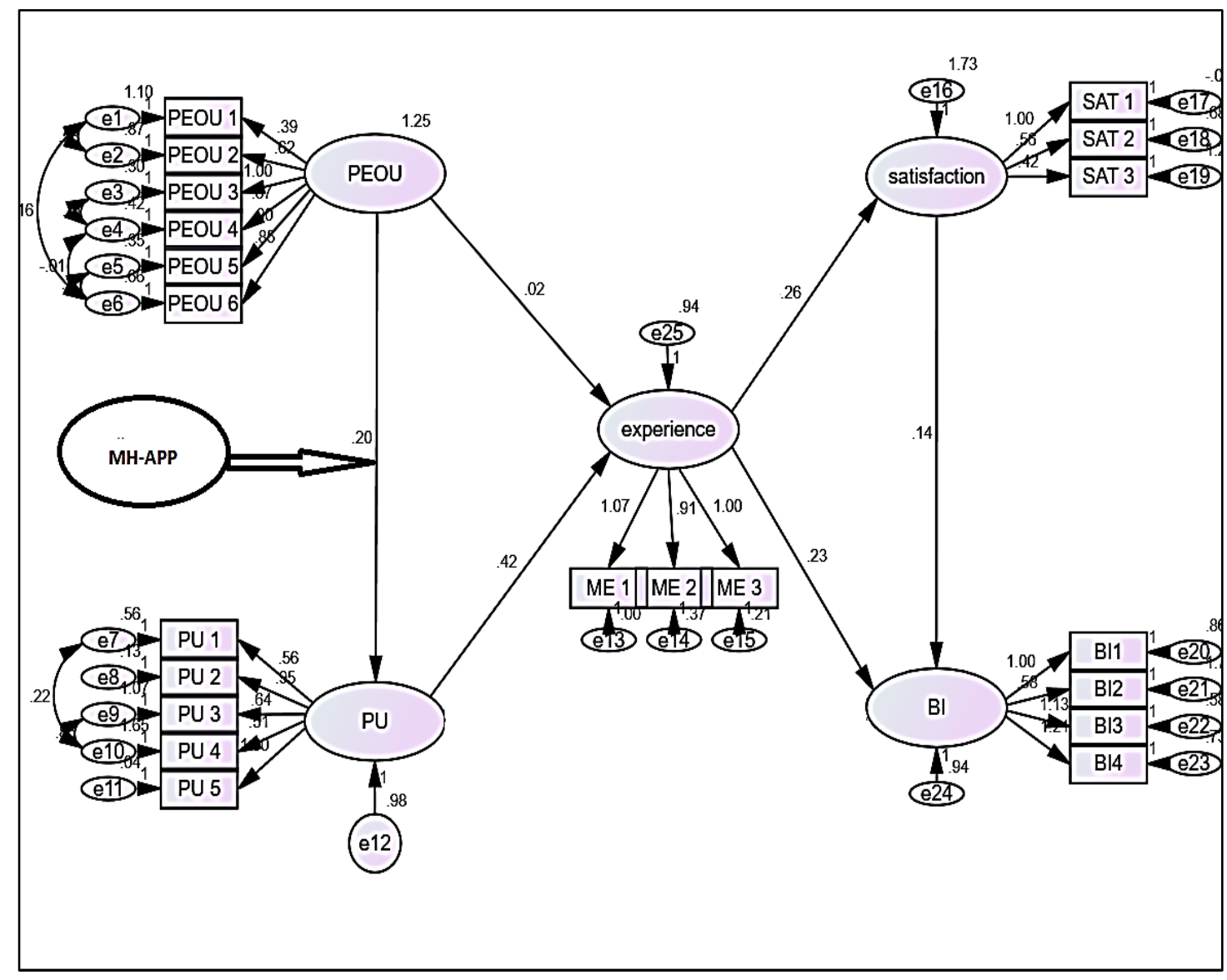

Fig.3. SEM-Path Analysis

\subsection{Structural model test}

Further path analysis was utilised to assess the hypothesised link in the model among variables, as shown in Table 3 and Figure 3. The results in Table 3 showed that five of the six hypotheses were significant and supported. SEM results shown that the influences of PEOU of mobile hotel apps on perceived usefulness were positive and significant $(\beta=.201, \mathrm{p}<.05)$. Thus, hypothesis 1 was confirmed.

The relationship between PEOU and memorable experience was insignificant. ( $\beta=$ $.020, \mathrm{p}>.05$ ). Accordingly, Hypothesis 2 was not supported. On the other hand, the strongest relationship was noticed to be Hypothesis 3, which examined the relationship between the perceived usefulness and memorable experience. $(\beta=.416, p$ $<.05)$. This result indicated that customer perceived usefulness from using branded mobile apps has a strong positive influence on a memorable experience. Memorable 
experiences had a significant impact on satisfaction $(\beta=.260, p<.05)$. These results supported Hypothesis 4, as well as supporting findings of a study conducted by De Oliveira and Mayer (2014), who found that "perceived usefulness" refers to tourists' belief that using mobile hotel apps will improve their experience.

Results supported Hypotheses 5 indicating a fairly strong relationship between memorable experience and behavioral intention $(\beta=.229, \mathrm{p}<.05)$. Further investigation of the study was performed on the sixth proposed hypothesis on whether there is a significant relationship between satisfaction and memorable experience towards BI. Findings in Table 3 confirmed that satisfaction and memorable experience $(\beta=0.139 ; \beta=0.229, p<.05)$ respectively were significantly related to $\mathrm{BI}$. Accordingly, H5 and H6 were verified and supported.

This finding emphasizes the significance of perceived usefulness, and memorable experience in constructing customer satisfaction and behavioral intention to re-use the mobile hotel app and revisit the hotel. This finding is consistent with previous research conducted by (Chen and Rahman, 2018; Eid et al., 2019; Seyfi et al., 2019) which showed that when a tourist has an outstanding memorable experience, he or she will be satisfied and have the behavioral intention to revisit. In addition, this finding is supported by Hsiao et al. (2016), who indicated that customer satisfaction, when combined with consistent service use, may be a critical component of a solid and loyal association among a hotel and its guests, as well as having a beneficial effect on future behavior intention. Individuals who are more satisfied are also more likely to demonstrate a strong desire to use apps on a frequent basis and reconsider their decision.

\section{Table 3}

Indicators of hypothesis evaluation.

\begin{tabular}{|c|c|c|c|c|}
\hline & Description & Estimate & p-values & Results \\
\hline $\mathrm{PU}$ & $<---$ PEOU & .201 & .003 & Accepted \\
\hline $\mathrm{ME}$ & $<---\quad$ PEOU & .020 & .767 & Rejected \\
\hline ME & $<---\quad P U$ & .416 & $* * *$ & Accepted \\
\hline Satisfaction & $<---\quad M E$ & .260 & .003 & Accepted \\
\hline BI & $<---\quad M E$ & .229 & .002 & Accepted \\
\hline BI & $<---$ satisfaction & .139 & .019 & Accepted \\
\hline
\end{tabular}

\section{5- Conclusion and discussion}

This study aims to investigate how technology acceptance variables in mobile hotel apps and tourist experience will elevate customer satisfaction and customer intention behavior to re-use the app in the hospitality industry. Furthermore, previous research on mobile hotel apps has not investigated the relationship between Technology Acceptance Model (TAM), and Memorable Experience (ME) model as drivers of satisfaction and customer behavioral intention in the hospitality field. As a result, this research developed an integrated model for predicting and interpreting customer intention in the context of mobile hotel apps. The model incorporates TAM, ME, and satisfaction customer behavioral intention formation, and thus addresses both the 
technical and behavioral aspects of mobile tourist apps. The findings of this study indicate that the TAM-based conceptual framework offers a comprehensive understanding of customers' behavior and intent to revisit and re-use mobile hotel apps.

The findings indicated that the mobile hotel apps construct, which consists of five variables, has adequate reliability for measuring mobile hotel apps. Perceived ease of use (PEOU) and perceived usefulness (PU) in particular have made significant contributions as key driving forces of acceptance and use of technology. Satisfaction and customer behavioral intention played crucial roles as key drivers of the tourist memorable experience (ME). The findings concurred with (Lin et al.,2012, Kim et al., 2011; Yuan et al., 2014; Hsiao et al., 2016).

This study found that PEOU had a significant positive impact on PU as predicted by TAM and supported by the results of the study $(\beta=0.201 ; \mathrm{p}<0.003)$, which is consistent with previous studies (Kulviwat et al., 2007; Moon and Kim, 2001). In other words, customers are more likely to decide that mobile applications were useful if they were simple to use and effortless. In addition, according to the findings of this study, introducing simple mobile hotel apps will not be enough to attract more customers to use the app. They must also develop a belief in the app's usefulness. Furthermore, hotels must create mobile hotel apps that are simple to use, effortless, secure, and private for their customers. As a result, management must concentrate on the development of such beliefs on the part of technology acceptance.

The study results related to $\mathrm{H} 2$, which states that perceived ease of use has a positive and direct effect on the memorable experience, were not significant. Accordingly, the results showed that there was no relationship between perceived ease of use and memorable experience in the mobile hotel app. Thus, hypothesis 2 was not supported $(\beta=.020, p>.05)$. In other words, customers' perception of how easy mobile hotel apps will be to use does not affect their experience. This result contradicted the results of previous studies conducted by Hong et al., 2006; Hsieh et al., 2008. In contrast, perceived usefulness had a positive and direct impact on memorable experience $(\beta=$ $0.416 ; \mathrm{p}<0.001)$. This finding highlights the fact that customers use mobile hotel apps because of the advantages they provide over other booking and service channels in the hotel. The findings support the notion that high-level smart tourism technology infrastructure will have a significant impact on memorable tourism experiences. Accordingly, the use of technology by customers may raise the level of memorable tourism experience. This finding is parallel with the previous studies conducted by Chung \& Kwon, (2009) and Alsamydai et al., (2014); they found that the use of the mobile app is determined by the technical support provided by the company as well as the level of experience of the customers who use it. The limited prior experience by the customer with mobile app services will contribute positively to the perceived usefulness. On the other hand, the mobile app experience is related to perceived usefulness. The experience influences consumers' attitudes, intentions, and use of mobile app services. 
The results show that a memorable tourism experience has a positive and direct effect on satisfaction and customer behavioral intention to re-use the app and revisit. This means that customers who have an exceptional experience will have significantly higher levels of satisfaction and behavioral intention to re-use the app and revisit the hotel. In other words, the tourist experience is a factor that directly mediates the relationship between technology acceptance of the mobile hotel app and resulting customer satisfaction, which, indirectly influences customer behavioral intention. This finding agreed with a study conducted by Kim (2018) about hotel smartphone apps. The study indicated that customers who experienced mobile hotel apps prior to arrival and during the stay are more likely to be satisfied with the hotel's contactless service and their post-stay relationship with the hotel may improve. Furthermore, the current findings confirm that customers' experience while using a Mobile hotel app is an important factor in determining their overall level of satisfaction and intention with the app. This conclusion is consistent with Wu and Liang's (2009) findings, which found substantial links between experiencing value, customers' satisfaction, and behavioral intention. Customers encounter and recognize numerous hotel services through experiential modules in hotel smartphone applications, and a positive experience with their experiential values may influence repurchase intentions.

The findings show that customer satisfaction influences customer intention to re-use the app and revisit in a positive and significant way $(\beta=0.139, \mathrm{p} 0.019)$, supporting hypothesis 6. with the harmony between customer satisfaction and customer experience. Thus, the findings revealed that client experience and consumer satisfaction had a critical impact on customers' intention to re-use the app and revisit the hotel. This finding agreed with Hsiao et al. (2016), who explained that Customers' satisfaction, along with continued use of services, may help a hotel build a strong and loyal engagement with its clients, as well as influence future behavior intentions.

\section{Implications}

As the COVID pandemic continues to have a significant effect on the hospitality and tourism industry, hotel companies are considering what they can do now and what they will do as regulations gradually ease. In most countries, restrictions will be progressively raised, and most customers will be concerned about issues such as excessive contact with hotel staff and other customers. Technologies such as mobile technology are already ingrained in the hotel industry, but they can be leveraged much further to develop business and customer satisfaction.

This study proposes strategies for competitiveness in the hospitality industry by utilizing mobile hotel apps. Understanding how and why a mobile app is used is important because it is a popular communication channel. Customers' engagement has an important influence on service businesses seeking to gain a competitive advantage (Tsiotsou, 2015). Considering the possible benefits of using this technology, more businesses have embraced branded apps (Jan and Contreras, 2011). Marriott, for example, includes a mobile request function in its app, allowing customers to request service before, during, or after their hotel stay (Wolf, 2017). 
According to the findings of this study, customers' perceptions and attitudes of ease of use are influenced by the perceived usefulness of new technology. The findings suggest that customers' behaviors toward new technology may have a significant impact on its usage and adoption during a stay. As a result, hotels should take into account the impact of external variables associated with new technological developments on customers' perceptions of usefulness and ease of use.

The positive relationships found between perceived usefulness, and memorable experiences show that perceived usefulness has critical, significant potential and offers opportunities for the hospitality industry to improve the customer experience and contribute to the overall experience.

Customers who had memorable moments after using the mobile hotel app and were satisfied at a specific brand hotel are more likely to return, re-use the app and recommend this hotel to their friends and other tourists. As a result, hotels must ensure that their customers' expectations are being met in a timely and appropriate manner. For instance, if a customer has a bad experience with mobile hotel app facilities, the customer may decide not to re-use the app and not to return and may not recommend this hotel to other tourists. Mobile hotel app structure is the primary factor influencing customers' experience and, as a result, increasing customer satisfaction and behavioral intention to re-use the app and revisit the hotel.

The findings could also help hospitality managers and app developers better realize the effects of mobile hotel apps on user satisfaction and behavioral intention. However, satisfaction may be contextual for app users. Thus, marketers should develop strategies that are appropriate for both actual and potential users.

\section{6- Study limitations and future research}

The study's findings highlight has been focused on customers who visited two major Egyptian cities namely, Cairo and Alexandria; thus, obtained results cannot be applied to all Egyptian hotels. As a result, expanding the study to include more cities and sample sizes may yield different findings and conclusions.

Unfortunately, the app system is not used in all hotels, and the majority of those that do are chain hotels. Because this is a quantitative study, using a mixed-method approach in a future research study with various demographic samples will work on improving the findings' reliability. Furthermore, MEs were measured as a single construct, so the findings cannot be generalized to the comprehensive perspective of MEs. As a result, future research should focus on measuring MEs as multidimensional constructs and their mediating role.

\section{REFERENCES}

Ali, F., Amin, M., Cobanoglu, C., 2016. An integrated model of service experience, emotions, satisfaction, and price acceptance: an empirical analysis in the Chinese hospitality industry. J. Hosp. Mark. Manage. 25 (4), 449-475

Alsamydai, Mahmood Jasim, Saad Galib Yassin, Husam Mustafa Alnaimi. Dima Mousa Dajani and Ihab Ali -Al Qirem. (2014). The factors influencing customer usage of mobile banking, International journal of business management \& research, Vo. 4, Issue 2, Apr 2014 pp 63-78 
Andreassen, T. W. \& Lindestad, B. (1998). Customer loyalty and complex services: The impact of corporate image on quality, customer satisfaction and loyalty for customers with varying degrees of service expertise. International journal of Service industry management, 9(1), 7-23.

Ayeh, J. (2015), “Travellers' acceptance of consumer generated media: an integrated model of technology acceptance and source credibility theories", Computers in Human Behavior, Vol. 48, pp. 173-180.

Benur, A.M. \& Bramwell, B. 2015. Tourism Management, 50(2015): 213-224.

Bogicevic, V., Bujisic, M., Bilgihan, A., Yang, W., \& Cobanoglu, C. (2016). The impact of traveler-focused airport technology on traveler satisfaction. Technological Forecasting and Social Change, (March), 0-1. https://doi.org/10.1016/j.techfore.2017.03.038

Bravo, R., Martinez, E., Pina, J.M., 2019. Effects of service experience on customer responses to a hotel chain. Int. J. Contemp. Hosp. Manage. 31 (1), 389-405.

Browne, M. W., \& Cudeck, R. (1993). Alternative ways of assessing model fit.Sociological Methods and Research, 21, 230-258.

Carlino, N. (2015). Virgin Hotels uses mobile app for an all-in-one experience. Hotel Business, 24(6), 24.

Chandralal, L., \& Valenzuela, F. (2013). Exploring memorable tourism experiences: Antecedents and behavioural outcomes. Journal of Economics, Business and Management, 1(2), 177-181.

Chandralal, L., Rindfleish, J., \& Valenzuela, F. (2015). An application of travel blog narratives to explore memorable tourism experiences. Asia Pacific Journal of Tourism Research, 20(6), 680-693.

Chen, C.H., Chang, Y.H. and Fan, F.C. (2012), "Adolescents and leisure activities: the impact of expectation and experience on service satisfaction", Social Behavior and Personality, Vol. 40 No. 2, pp. 259-265.

Chen, H. and Rahman, I. (2018), "Cultural tourism: an analysis of engagement, cultural contact, memorable tourism experience and destination loyalty", Tourism Management Perspectives, Vol. 26, pp. 153-163.

Chin, W. W. (2010). How to write up and report PLS analyses. In V. E. Vinzi, W. W. Chin, J. Henseler \& H. Wang (Eds.), Handbook Of Partial Least Squares: Concept, Methods And Applications (pp. 655-690). Berlin, Germany: SpringerVerlag.

Chu, R., 2002. Stated-importance versus derived-importance customer satisfaction measurement. Journal of Services Marketing, 16(4), pp.285-301.

Chung, N., \& Kwon, S.J. (2009). The Effects of Customers' Mobile Experience and Technical Support on the Intention to Use Mobile Banking. Cyber psychology \& behavior : the impact of the Internet, multimedia and virtual reality on behavior and society, 12 5, 539-43 .

Chung, N., Lee, H., Kim, J.Y., Koo, C., 2018. The role of augmented reality for experience-influenced environments: the case of cultural heritage tourism in Korea. J. Travel. Res. 57 (5), 627-643.

Cornelisse, M. (2014) 'Memorable tourist experiences in authentic Vicos, Peru', Journal of Tourism Consumption and Practice, 6(1), p.104-127 
Davis, F.D. (1986), “Technology acceptance model for empirically testing new enduser information systems theory and feature. Journal of Travel Research, 45(2), 204-216. https://doi.org/10.1177/0047287506291599

Davis, FD. (1989). Perceived Usefulness, Perceived Ease of Use, and User Acceptance of Information Technology. MIS Quaterly,13(3): 319-340.

De Cannière, M.H., De Pelsmacker, P. \& Geuens, M. 2010. Relationship quality and purchase intention and behaviour: The moderating impact of relationship strength. Journal of Business and Psychology, 25(1): 87-98.

De Oliveira Nunes, M., \& Mayer, V. F. (2014). Mobile technology, games and nature areas: The tourist perspective. Tourism and Management Studies, 10(1), 53-58.

Dickinson, J. E., Ghali, K., Cherrett, T., Speed, C., Davies, N., \& Norgate, S. (2014). Tourism and the smartphone app: capabilities, emerging practice and scope in the travel domain. Current Issues In Tourism, 17(1), 84-101. doi:10.1080/13683500.2012.718323

Dube, A. and Helkkula, A., 2015. Service experiences beyond the direct use: indirect customer use experiences of smartphone apps. Journal of Service Management, 26(2), pp.224-248.

Eid, R., El-Kassrawy, Y.A. and Agag, G. (2019), "Integrating destination attributes, political (in) stability, destination image, tourist satisfaction, and intention to recommend: a study of UAE", Journal of Hospitality and Tourism Research, Vol. 43 No. 6, pp. 839-866.

Fang, Zhao, Wen, \& Wang. (2017). Design and performance attributes driving mobile travel application engagement. International Journal of Information Management, 37(4), 269-283.

Femenia-Serra, F. and Ivars-Baidal, J.A. (2018), "Do smart tourism destinations really work? The case of Benidorm", Asia Pacific Journal of Tourism Research: pp. $1-20$.

Flavián, C., Guinalíu, M. \& Gurrea, R. 2006. The role played by perceived usability, satisfaction and consumer trust on website loyalty. Information \& Management, 43(1): 1-14.

Fornell, C., \& Larcker, D. F. (1981). Evaluating structural equation models with unobservable variables and measurement error. Journal of Marketing Research, 18(1), 39-50.

Gallarza, MG \& Saura, IG. (2006). Value dimensions, perceived value, satisfaction and loyalty: an investigation of university students' travel behavior. Tourism Management 27(3): 437-452.

Gamboa, A.M. and Gonçalves, H.M., 2014. Customer loyalty through social networks: Lessons from Zara on Facebook. Business Horizons, 57(6), pp.709717.

Han, H., Ryu, K., 2009. The roles of the physical environment, price perception, and customer satisfaction in determining customer loyalty in the restaurant industry. J. Hosp. Tour. Res. 33 (4), 487-510.

Herrero, A. \& Martin, H.S., 2012, 'Developing and testing a global model to explain the adoption of websites by users in rural tourism accommodations', 
International Journal of Hospitality Management 31(1), 1178-1186. https://doi.org/10.1016/j. ijhm.2012.02.005

Hong, S. J., Thong, J., \& Tam, K. Y. (2006). Understanding continued information technology usage behavior: a comparison of three models in the context of mobile internet. Decision Support Systems, 42, 1819-1834

Hsiao, C., Chang, J. and Tang, K. (2016), "Exploring the influential factors in continuance usage of mobile social apps: satisfaction, habit, and customer value perspectives", Telematics and Informatics, Vol. 33No. 2, pp. 342-355.

Hsieh, J., Rai, A., \& Keil, M. (2008). Understanding digital inequality: comparing continued use behavioral models of the socio-economically advantaged and disadvantaged. MIS Quarterly, 32(1), 97-126.

Huber, F., A. Herrmann, and R. E. Morgan. 2001. Gaining competitive advantage through customer value oriented management. Journal of Consumer Marketing 18(1): 41-53.

Jan, A. and Contreras, V. (2011), "Technology acceptance model for the use of information technology in universities", Computers in Human Behavior, Vol. 27 No. 2, pp. 845-851.

Jeong, M. and Shin, H.H. (2019), "Tourists' experiences with smart tourism technology at smart destinations and their behavior intentions", Journal of Travel Research, p. 0047287519883034.

Jeong, M.; Shin, H.H. Tourists' experiences with smart tourism technology at smart destinations and their behavior intentions. J. Travel Res. 2019. [CrossRef]

Jiang, Y., Ramkissoon, H. and Mavondo, F. (2016), "Destination marketing and visitor experiences: the development of a conceptual framework", Journal of Hospitality Marketing and Management, Vol. 25 No. 6, pp. 653-675.

Jin, N., Lee, S., \& Lee, H. (2015). The effect of experience quality on perceived value, satisfaction, image and behavioral intention of water park patrons: New versus repeat visitors: The effect of experience quality. International Journal of Tourism Research, 17(1), 82-95.

Kao, T.-W.D. \& Lin, W.T. 2016. The relationship between perceived e-service quality and brand equity: A simultaneous equations system approach. Computers in Human Behaviour, 57: 208-218.

Kaplanidou, K., \& Vogt, C. (2006). A structural analysis of destination travel intentions as a function of web site

Kim, H. (2018). The effects of hotel smartphone applications on hotel guest satisfaction and re-use intention: an experiential value approach. A Thesis, Master of Science in Hospitality Management. The Collins College of Hospitality Management

Kim, H. and Chen, J.S. (2019), "The memorable travel experience and its reminiscence functions", Journal of Travel Research, Vol. 58 No. 4, pp. 637-649.

Kim, J. \& Ah Yu, E. 2016. The Holistic Brand Experience of Branded Mobile Applications Affects Brand Loyalty. Social Behaviour and Personality: an International Journal, 44(1): 77-87. DOI: 10.2224/sbp.2016.44.1.77. 
Kim, J. (2016). An extended technology acceptance model in behavioral intention toward hotel tablet apps with moderating effects of gender and age. International Journal of Contemporary Hospitality Management, 28(8), 1535-1553.

Kim, J., Ritchie, J. R. B., \& Tung, W. S. V. (2010). The effect of memorable experience on behavioral intentions in tourism: A structural equation modeling approach. Tourism Analysis, 15, 637-648.

Kim, J.H. (2018), "The impact of memorable tourism experiences on loyalty behaviors: the mediating effects of destination image and satisfaction", Journal of Travel Research, Vol. 57 No. 7, pp. 856-870.

Kim, J.-H. and Ritchie, J.B. (2014), "Cross-cultural validation of a memorable tourism experience scale (MTES)", Journal of Travel Research, Vol. 53 No. 3, pp. 323-335.

Kim, J.-H., Ritchie, J.B. and McCormick, B. (2012), "Development of a scale to measure memorable tourism experiences", Journal of Travel Research, Vol. 51 No. 1, pp. 12-25.

Kim, M. and Qu, H. (2014), “Travelers' behavioral intention toward hotel self-service kiosks usage", International Journal of Contemporary Hospitality Management, Vol. 26 No. 2, pp. 225-245.

Kim, Y. H., Kim, M., \& Goh, B. K. (2011). An examination of food tourist's behavior: Using the modified theory of reasoned action. Tourism Management, 32(5), 1159-1165.

Kulviwat, S., Bruner, G.C., Kumar, A., Nasco, S., \& Clark, T. (2007). Toward a unified theory of consumer acceptance technology. Psychology \& Marketing, 24, 1059-1084.

Kwon, J.M., Bae, J.I. and Blum, S.C. (2013), "Mobile applications in the hospitality industry", Journal of Hospitality and Tourism Technology, Vol. 4 No. 1, pp. 8192.

Lee, H., Lee, J., Chung, N. and Koo, C. (2018), "Tourists' happiness: are there smart tourism technology effects?", Asia Pacific Journal of Tourism Research, Vol. 23 No. 5, pp. 486-501.

Lee, SY., Petrick, JF., Crompton, J. (2007). The roles of quality and intermediary constructs in determining festival attendees' behavioural intention. Journal of Travel Research 45(4): 402-412.

Lee, Y. (2015). Creating memorable experiences in a reuse heritage site. Annals of Tourism Research, 55, 155-170. http://doi.org/10.1016/j.annals.2015.09.009

Lehto, X.Y., O'Leary, J.T. and Morrison, A.M. (2004), "The effect of prior experience on vacation behavior", Annals of Tourism Research, Vol. 31 No. 4, pp. 801-818.

Lin, P. (2015, September 10). Why mobile apps have the advantage in hotel guest engagement. Retrieved November 22, 2016, from http://ehotelier.com/insights/2015/09/10/why-mobile-apps-have-the- advantagein-hotel-guest-engagement/

Lin, T.-C., Wu, S., Hsu, J.S.-C. \& Chou, Y.-C. 2012. The integration of value-based adoption and expectation-confirmation models: An example of IPTV continuance intention. Decision Support Systems, 54(1): 63-75. 
Manthiou, A., Kang, J., Chiang, L., \& Tang, L. (Rebecca). (2016). Investigating the effects of memorable experiences: An extended model of script theory. Journal of Travel \& Tourism Marketing, 33(3), 362-379. http://doi.org/10.1080/10548408.2015.1064055

Martín-Consuegra, D., Molina, A., Esteban, 'A., 2007. An integrated model of price, satisfaction and loyalty: an empirical analysis in the service sector. J. Prod. Brand. Manage. 16 (7), 459-468.

Meuter, M.L., Ostrom, A.L., Roundtree, R.I. and Bitner, M.J. (2000), "Self-service technologies: understanding customer satisfaction with technology-based service encounters", Journal of Marketing, Vol. 64 No. 3, pp. 50-64.

Moon, Jm \& Kim, Y.G (2001). Extending the TAM for a world-wide-web context, information and management, 28, pp217-230.

Pantano, E. \& Viassone, M. 2015. Engaging consumers on new integrated multichannel retail settings: Challenges for retailers. Journal of Retailing and Consumer Services, 25: 106-114.

Serenko, A. and Bontis, N. (2004), "A model of user adoption of mobile portals", Quarterly Journal of Electronic Commerce, Vol. 4 No. 1, pp. 69-98.

Seyfi, S., Hall, C.M. and Rasoolimanesh, S.M. (2019), "Exploring memorable cultural tourism experiences", Journal of Heritage Tourism: Vol. 15 No. 3, pp. 117.

Tsiotsou, R.H. (2015). The role of social and parasocial relationships on social networking sites loyalty. Comput. Hum. Behav., 48, 401-414.

Tung, V. W. S., Lin, P., Qiu Zhang, H., \& Zhao, A. (2016). A framework of memory management and tourism experiences. Journal of Travel \& Tourism Marketing, 00(00), 1-14.

Tung, V.W.S. and Ritchie, J.B. (2011), "Exploring the essence of memorable tourism experiences", Annals of Tourism Research, Vol. 38 No. 4, pp. 1367-1386.

Tussyadiah, I.P., Park, S., 2018. Consumer evaluation of hotel service robots. Information and Communication Technologies in Tourism 2018. Springer, Cham, pp. 308-320

Vada, S., Prentice, C., \& Hsiao, A. (2019). The influence of tourism experience and wellbeing on place attachment. Journal of Retailing and Consumer Services, 47, 322-330

Veloutsou, C. 2015. Brand evaluation, satisfaction and trust as predictors of brand loyalty: the mediator-moderator effect of brand relationships. Journal of Consumer Marketing, 32(6): 405-421.

Wang, D., Xiang, Z., Law, R., \& Ki, T. P. (2016). Assessing hotel-related smartphone apps using online reviews. Journal of Hospitality Marketing \& Management,25(3), 291-313.

Wang, H.Y. and Wang, S.H. (2010), "Predicting mobile hotel reservation adoption: insight from a perceived value standpoint", International Journal of Hospitality Management, Vol. 29 No. 4, pp. 598-608.

Wirtz, D., Kruger, J., Scollon, C. N., \& Diener, E. (2003). What to do on spring break? The role of predicted, on-line, and remembered experience in future choice. Psychological Science, 14, 520-524.

Wolf, J. (2017), "Marriott reimagines its mobile app to meet the needs of modern world travellers", retrieved from: http://news.marriott.com/2017/02/marriott-reimaginesmobileapp- meet-needs-modern-world-travellers/ 
Wu, C., \& Liang, R. (2009). Effect of experiential value on customer satisfaction with service encounters in luxury-hotel restaurants. International Journal of Hospitality Management, 28(4), 586-593.

Yang, H.C., 2013. Bon appétit for apps: young American consumers' acceptance of mobile applications. Journal of Computer Information Systems, 53(3), pp.85-96.

Yi, J. 1990. A critical review of consumer satisfaction. In Review of Marketing edited by Valarie.A. Zeithaml. Chicago: American Marketing Association.

Yuan, S., Liu, Y., Yao, R. \& Liu, J. 2014. An investigation of users' continuance intention towards mobile banking in China. Information Development. 266666914522140. Development. 266666914522140.

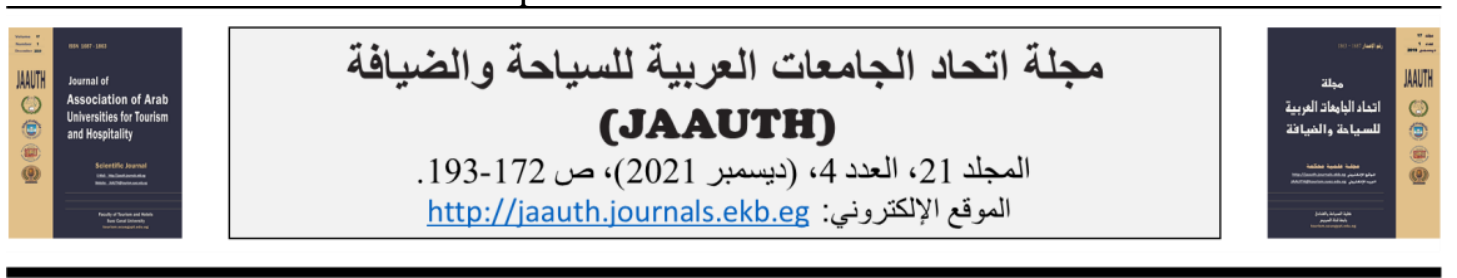

\section{آثار تطبيقات الهواتف الأكية بالفنادق على النية السلوكية للعملاء لإعادة الاستخدام والزيارة}

\section{ماهر حسني}

قسم إدارة الفنادق، معهد القاهرة العالي للسياحة والفنادق.

\begin{tabular}{|c|c|}
\hline الملخص & معلومات المقالة \\
\hline 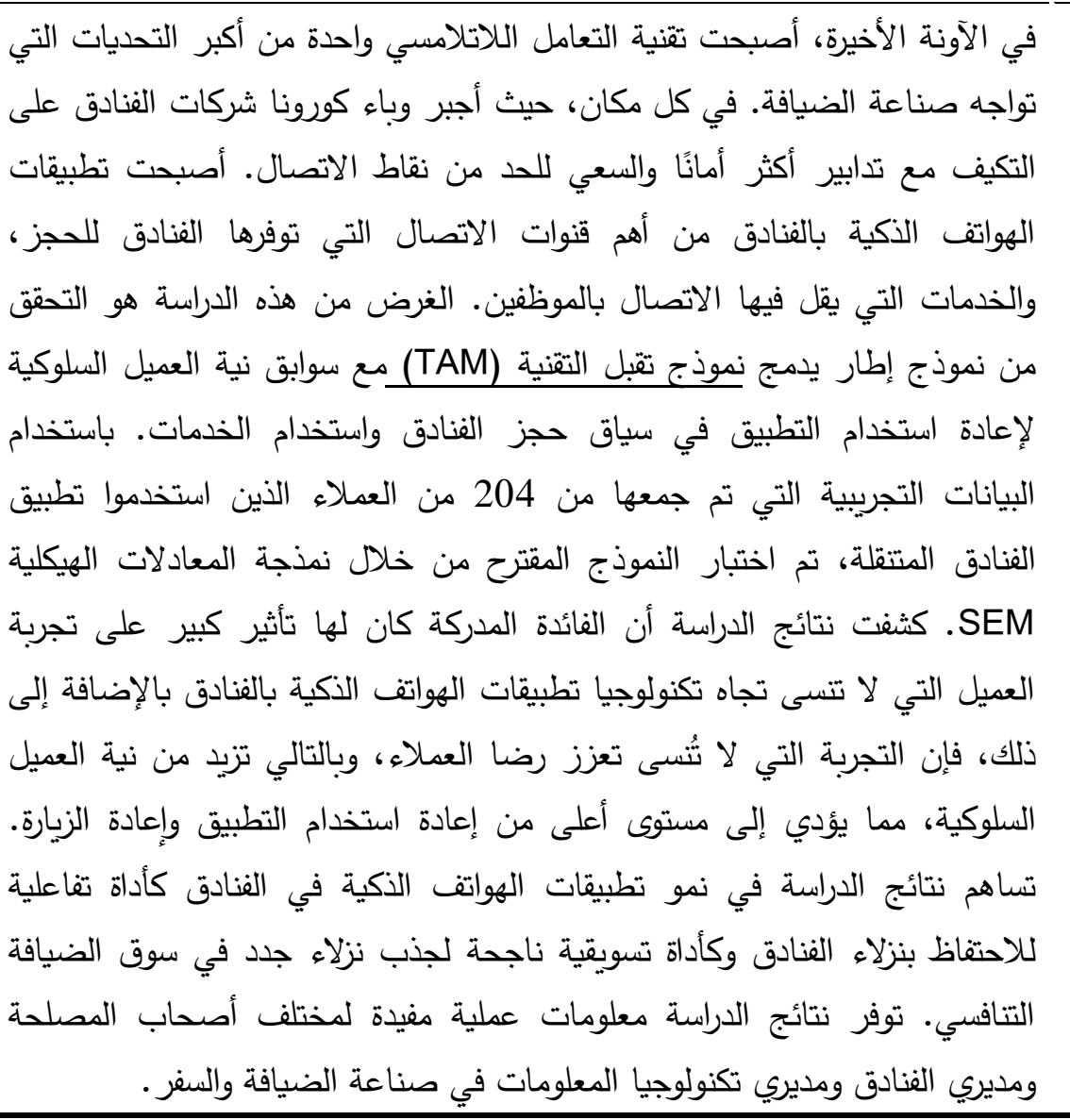 & 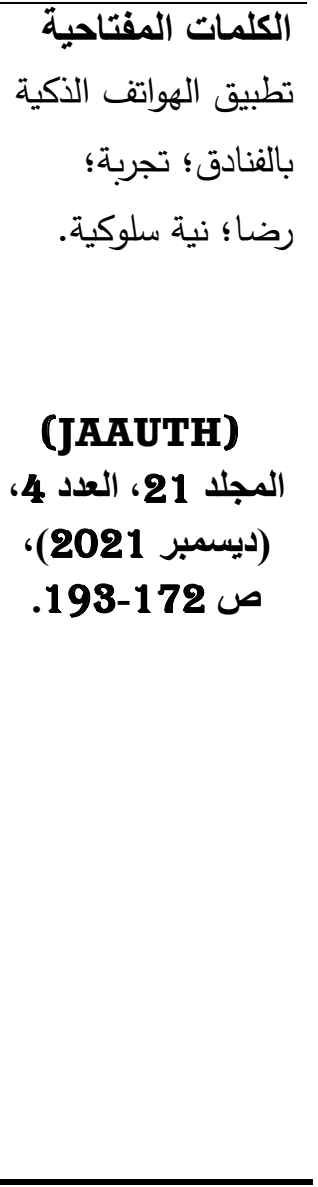 \\
\hline
\end{tabular}

